Check for updates

Cite this: RSC Adv., 2017, 7, 38458

Received 30th June 2017 Accepted 30th July 2017

DOI: $10.1039 / c 7 r a 07247 c$

rsc.li/rsc-advances

\title{
A benzimidazole functionalized NDI derivative for recyclable fluorescent detection of cyanide in water $\dagger$
}

\author{
Qi Lin, (DD *a Lu Liu, ${ }^{a}$ Feng Zheng, ${ }^{a}$ Peng-Peng Mao, ${ }^{a}$ Juan Liu, ${ }^{\star b}$ You-Ming Zhang, (D) ${ }^{a}$ \\ Hong Yao and Tai-Bao Wei (iD *a
}

\begin{abstract}
A fluorescent chemosensor (L2) has been designed and synthesized via a simple one step reaction through rationally combining benzimidazole and naphthalene diimide (NDI) moieties together. The structure of L2 has been confirmed by single crystal X-ray diffraction. The sensor L2 shows a highly selective and sensitive fluorescence response for $\mathrm{CN}^{-}$. Upon the addition of a $\mathrm{CN}^{-}$water solution into the DMSO solution of sensor L2, the solution of L2 shows an instant fluorescence enhancement and other anions couldn't interfere in the $\mathrm{CN}^{-}$detection process. The $\mathrm{CN}^{-}$sensing process shows reversible properties by adding $\mathrm{H}^{+}$into the sensor $\mathrm{L} 2$ solution treated by $\mathrm{CN}^{-}$. The detection limit of the sensor towards $\mathrm{CN}^{-}$is $8.32 \times$ $10^{-7} \mathrm{M}$, which could be distinguished by the naked eye in a UV lamp. The sensor L2 could serve as a practical and convenient recyclable test kit to detect $\mathrm{CN}^{-}$.
\end{abstract}

\section{Introduction}

As we all know, ions play a fundamental role in many chemical, biological, medical and technological processes. ${ }^{1-9}$ Cyanide ions $\left(\mathrm{CN}^{-}\right)$are one of the most toxic anions, being extremely harmful to the environment and human health. ${ }^{\mathbf{1 0 - 1 2}}$ When cyanide enters the body by oral, inhalation or dermal exposure, it exerts its acute effects by complexing with ferric iron atoms in metalloenzymes, resulting in histotoxic anoxia through inhibition of cytochrome $\mathrm{c}$ oxidase. The maximum permissive level of cyanide in drinking water is therefore set at as low as $1.9 \mathrm{mM}$ by the World Health Organization (WHO). ${ }^{13}$ However, large quantities of cyanide salts are widely used in industrial settings such as metallurgy, electroplating, and the synthesis of fine chemicals. In addition, a higher level of cyanide can also be accumulated through the consumption of certain foods and plants. ${ }^{14}$ Therefore, much interest has been sparked in the design of new methods to monitor $\mathrm{CN}^{-}$in biological and environmental samples.

Thanks to the enthusiastic efforts of scientists, a large number of good sensors for cyanide have been invented. ${ }^{\mathbf{1 5 , 1 6}}$ Among the various sensors, fluorescent chemosensors present

${ }^{a}$ Key Laboratory of Eco-Environment-Related Polymer Materials, Ministry of Education of China, Key Laboratory of Polymer Materials of Gansu Province, College of Chemistry and Chemical Engineering, Northwest Normal University, Lanzhou, Gansu, 730070, P. R. China.E-mail: linqi2004@126.com; weitaibao@126.com

${ }^{b}$ College of Chemical Engineering, Northwest University for Nationalities, Lanzhou, 730000, P. R. China. E-mail: liujuan656@126.com

$\dagger$ Electronic supplementary information (ESI) available. See DOI: $10.1039 / \mathrm{c} 7 \mathrm{ra07247c}$ numerous advantages, including high sensitivity, low cost, and easy operation. ${ }^{17-19}$ Several fluorescent chemosensor systems for $\mathrm{CN}^{-}$detection reported to date are based on the mechanism of coordination, ${ }^{20-24}$ hydrogen-bonding interactions, ${ }^{25-27}$ nucleophilic addition reactions, ${ }^{28-36}$ sonogashira cross-coupling reaction $^{37-39}$ and so on. However, most of the $\mathrm{CN}^{-}$sensors often employ sophisticated structures and require complicated synthetic steps and high temperature or a long reaction time for detection of $\mathrm{CN}^{-}$. Thus, developments of simple and high efficiency fluorescent chemosensor for detecting $\mathrm{CN}^{-}$are very necessary.

In view of these and as a part of our research interests in ion recognition, ${ }^{\mathbf{4 0 - 4 8}}$ we attempt to develop an easy-to-make and efficient fluorescent chemosensor which can sense $\mathrm{CN}^{-}$with specific selectivity and high sensitivity. Herein, we report a benzimidazole functionalized NDI-based ${ }^{49}$ fluorescent chemosensor $\mathbf{L} 2$ which could be obtained from an easy one step reaction (Scheme 1). The sensor $\mathbf{L} 2$ could efficiently detect $\mathrm{CN}^{-}$ in water under mild conditions via a deprotonation and electric charge transferring mechanism, which could be used for highly selective and sensitive fluorescence enhancement detection of cyanide in aqueous media (Scheme 1).

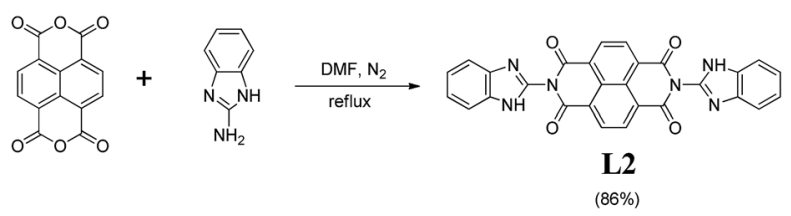

Scheme 1 Synthesis of the sensor molecule L2. 


\section{Experimental}

The fluorescent chemosensor $\mathbf{L 2}$ was synthesized through a simple one-step reaction (Scheme 1). 1,4,5,8-naphthalenetetracarboxylic dianhydride $(2.68 \mathrm{~g}, 10 \mathrm{mmol})$ and 2-aminobenzimidazole (2.66 g, $20 \mathrm{mmol})$ were mixed in DMF $(25 \mathrm{~mL})$ in a round-bottom flask $(50 \mathrm{~mL})$. The reaction mixture was stirred at $120{ }^{\circ} \mathrm{C}$ for $24 \mathrm{~h}$. After cooling to room temperature, the mixture was poured into $\mathrm{H}_{2} \mathrm{O}(15 \mathrm{~mL})$. The precipitate was collected by filtration, washed with ethanol $(20 \mathrm{~mL} \times 3)$, and then dried in vacuum, give a yellow powder compound $\mathbf{L 2}$. Yield: 4.43 g. $86 \% . \mathrm{mp}>300{ }^{\circ} \mathrm{C} .{ }^{1} \mathrm{H}$ NMR (600 MHz, DMSO- $d_{6}$, Fig. S1†) $\delta 12.68(\mathrm{~s}, 2 \mathrm{H}), 8.83(\mathrm{~s}, 4 \mathrm{H}), 7.69(\mathrm{dd}, J=12.0,6.0 \mathrm{~Hz}$, $4 \mathrm{H}$ ), 7.33 (dd, $J=12.0,6.0 \mathrm{~Hz}, 4 \mathrm{H}) .{ }^{13} \mathrm{C}$ NMR (150 MHz, DMSO$d_{6}$, Fig. S2 $\left.\dagger\right){ }^{13} \mathrm{C}$ NMR $\left(150 \mathrm{MHz}, \mathrm{DMSO}-d_{6}\right) \delta 162.95,142.27$, 141.16, 134.38, 131.68, 127.59, 126.97, 123.70, 122.31, 119.85, 112.52. IR (KBr, Fig. S3†) v: $1330(-\mathrm{C}=\mathrm{N}-), 1681(-\mathrm{C}=\mathrm{O}), 3509$ $(-\mathrm{NH}) \mathrm{cm}^{-1}$. MS: ESI $\mathrm{m} / z$ for $\mathbf{L 2}\left[\mathrm{C}_{28} \mathrm{H}_{14} \mathrm{~N}_{6} \mathrm{O}_{4}+\mathrm{H}\right]^{+}$found: 499.01, calcd: 499.11 (Fig. S4†).

The structure of the sensor was further confirmed by singlecrystal X-ray diffraction. The single crystal (CCDC: 1553559) was obtained by slowly vaporizing the DMSO solution of L2. As shown in Fig. 1a, in the molecular of $\mathbf{L 2}$, the benzimidazole

(a)

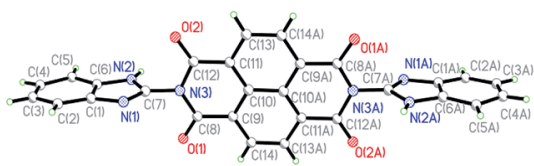

(b)

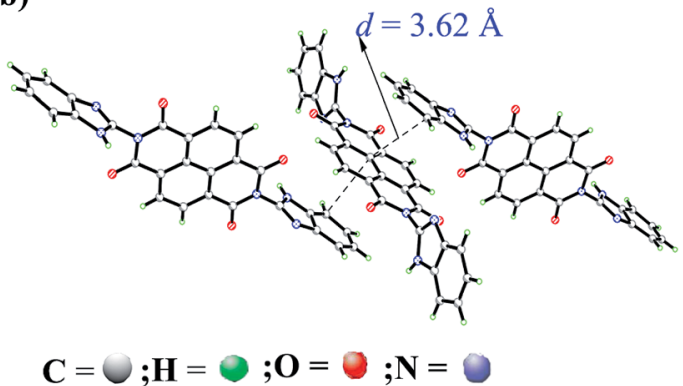

Fig. 1 Different perspectives of L2's crystal structure.

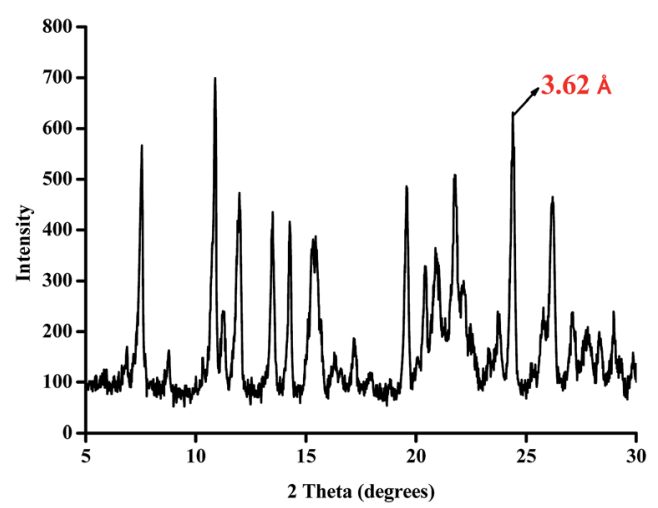

Fig. 2 XRD diagram of the sensor of L2. moiety and the naphthalene diimide (NDI) moiety don't on one plan. The dihedral angle of benzimidazole group and naphthalene diimide (NDI) moiety is $99.1^{\circ}$. Moreover, as shown in Fig. 1b, the benzimidazole moiety of one molecular of $\mathbf{L} 2$ shows parallel stacking with naphthalene diimide (NDI) moiety on adjacent molecular of $\mathbf{L 2}$. The distance between the two plan is $3.62 \AA$, which indicate that there are intermolecular $\pi-\pi$ interaction $^{50}$ existing among the neighboring $\mathbf{L} 2$ molecular. In addition, in the powder the X-ray diffraction (XRD) of L2 (Fig. 2), we observed a sharp diffraction peak with $d$-spacing of $3.62 \AA$ at $2 \theta=24.42^{\circ}$, which suggested that $\pi-\pi$ stacking exists between the between molecular of $\mathbf{L} 2$.

\section{Results and discussion}

In order to investigate the anion recognition abilities of the sensor $\mathbf{L} 2$ in water, we carried out a series of host-guest recognition experiments. The recognition profiles of the chemosensor $\mathbf{L} 2$ toward various anions, including $\mathrm{F}^{-}, \mathrm{Cl}^{-}, \mathrm{Br}^{-}, \mathrm{I}^{-}$, $\mathrm{AcO}^{-}, \mathrm{H}_{2} \mathrm{PO}_{4}{ }^{-}, \mathrm{HSO}_{4}{ }^{-}, \mathrm{ClO}_{4}{ }^{-}$and $\mathrm{CN}^{-}$, were primarily investigated using fluorescence spectroscopy. As shown in Fig. 3, in the fluorescence spectrum of L2 DMSO solution, the maximum emission of $\mathbf{L} 2$ appeared at $510 \mathrm{~nm}$ in water when excited at $\lambda_{\text {ex }}=455 \mathrm{~nm}$. When 10 equiv. of $\mathrm{CN}^{-}$water solution was added to the DMSO solution of sensor $\mathbf{L} 2$, the fluorescence emission band at shifted to $550 \mathrm{~nm}$ and shows obvious enhancement. The apparent fluorescence emission change could be distinguished by the naked eye under UV lamp (Fig. 3). To validate the selectivity of sensor $\mathbf{L 2}$, the same tests were also conducted using $\mathrm{F}^{-}, \mathrm{Cl}^{-}, \mathrm{Br}^{-}, \mathrm{I}^{-}, \mathrm{AcO}^{-}, \mathrm{H}_{2} \mathrm{PO}_{4}{ }^{-}, \mathrm{HSO}_{4}{ }^{-}, \mathrm{ClO}_{4}{ }^{-}$ions, and none of these anions induced any significant changes in the fluorescent spectrum of the sensor (Fig. 4). Therefore, the sensor $\mathbf{L} 2$ could selectively sense $\mathrm{CN}^{-}$in water solution.

To further investigate the $\mathrm{CN}^{-}$detection property of the sensor $\mathbf{L 2}$, the fluorescence emission spectral variation of $\mathbf{L} 2$ in DMSO/ $\mathrm{H}_{2} \mathrm{O}(9: 1, \mathrm{v} / \mathrm{v})$ HEPES buffered solution was monitored during titrations with different concentrations of $\mathrm{CN}^{-}$in water from 0 to 25 equivalents (Fig. 5). With an increasing amount of

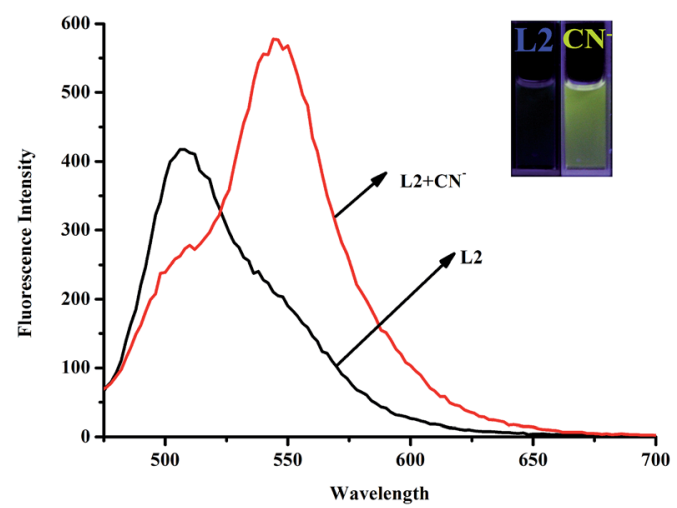

Fig. 3 Fluorescence spectra of $\mathrm{L} 2(20 \mathrm{mM})$ upon excitation at $455 \mathrm{~nm}$ DMSO $/ \mathrm{H}_{2} \mathrm{O}(9: 1, \mathrm{v} / \mathrm{v})$ before and after addition of $\mathrm{CN}^{-}$(50 equiv.) water solution. Inset: Photographs showing the change in the fluorescence of $\mathrm{L} 2$ after addition of $\mathrm{CN}^{-}$(10 equiv.) in $\mathrm{DMSO} / \mathrm{H}_{2} \mathrm{O}$ (9:1, v/v) HEPES buffered solution. 


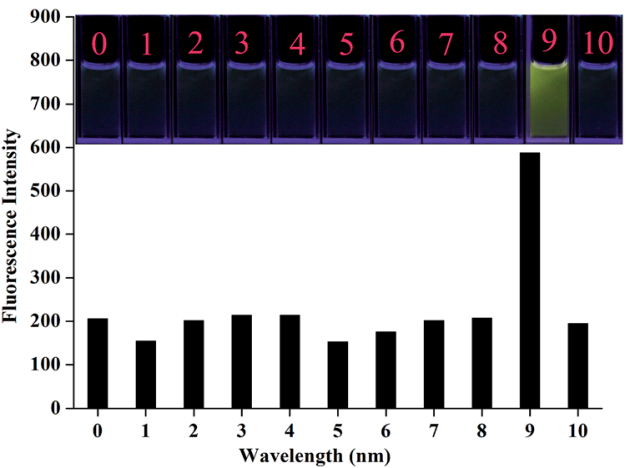

Fig. 4 Histogram of fluorescence emission of $L 2\left(c=2 \times 10^{-5} \mathrm{M}\right)$ in the presence of various anions ( 50 equiv., $\lambda_{\mathrm{ex}}=455 \mathrm{~nm}$ ) in DMSO $/ \mathrm{H}_{2} \mathrm{O}$ ( $9: 1 \mathrm{v} / \mathrm{v})$ HEPES buffered solution. Inset: Color changes observed for $\mathrm{L} 2$ upon the addition of various anions in water. From 0 to $10: \mathrm{L}^{2} \mathrm{Cl}^{-}$, $\mathrm{Br}^{-}, \mathrm{I}^{-}, \mathrm{H}_{2} \mathrm{PO}_{4}^{-}, \mathrm{F}^{-}, \mathrm{AcO}^{-}, \mathrm{HSO}_{4}^{-}, \mathrm{ClO}_{4}^{-}, \mathrm{CN}^{-}, \mathrm{SCN}^{-}$.

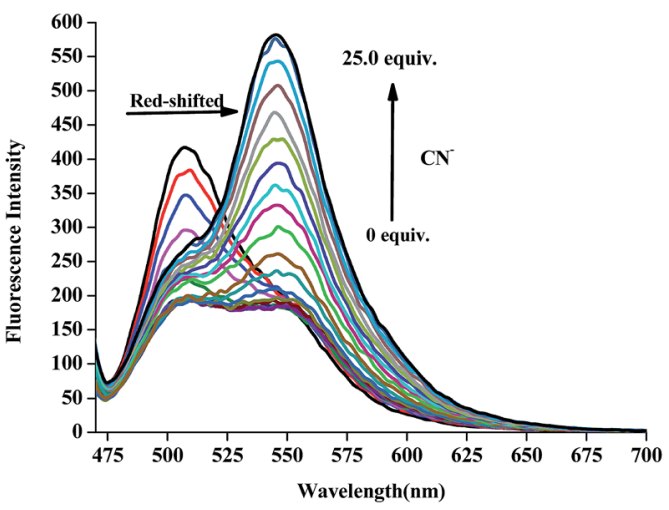

Fig. 5 Fluorescence spectra of $\mathrm{L} 2$ in the presence of different concentrations of $\mathrm{CN}^{-}$in DMSO/H $\mathrm{H}_{2} \mathrm{O}(9: 1, \mathrm{v} / \mathrm{v})$ HEPES buffered solution.

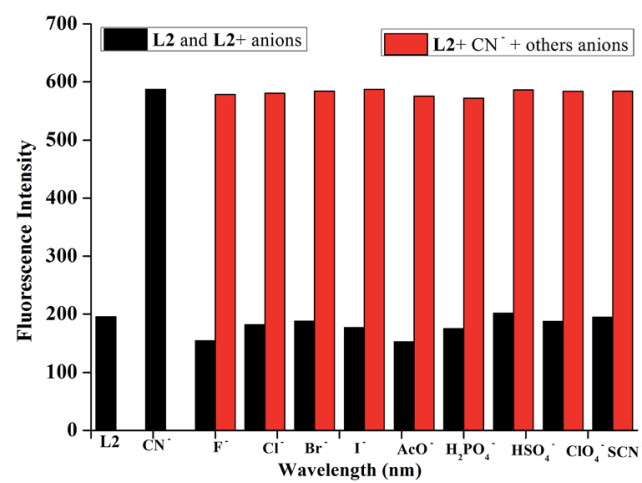

Fig. 6 Fluorescence intensity at $587 \mathrm{~nm}$ of $\mathrm{L} 2\left(\mathrm{c}=2 \times 10^{-5} \mathrm{M}\right)$ exposed to 50 equiv. various anions and to the mixture of 10 equiv. $\mathrm{CN}^{-}$with other 50 equiv. ions in DMSO/ $\mathrm{H}_{2} \mathrm{O}(9: 1, \mathrm{v} / \mathrm{v}) \mathrm{HEPES}$ buffered solution.

$\mathrm{CN}^{-}$, the emission peak at $510 \mathrm{~nm}$ gradually shows a bathochromic effect, however, the emission peak at $550 \mathrm{~nm}$ increased. The scatter plot indicated that the reaction basic

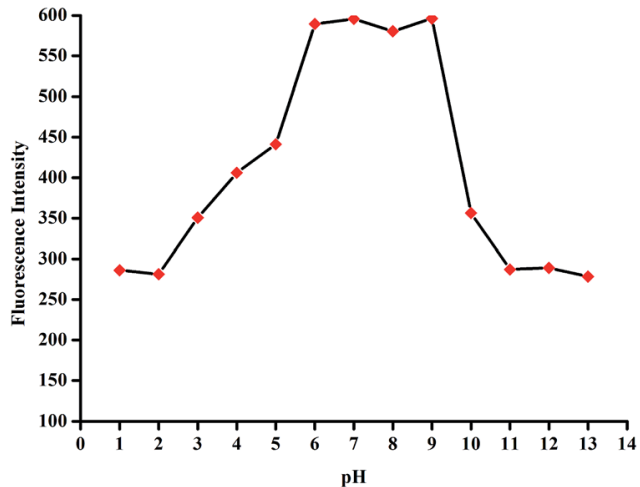

Fig. 7 Influence of $\mathrm{pH}$ on the fluorescence of $\mathrm{L} 2-\mathrm{CN}^{-}\left(c=2.0 \times 10^{-5} \mathrm{M}\right)$ in HEPES buffered solution in DMSO/ $\mathrm{H}_{2} \mathrm{O}(9: 1, \mathrm{v} / \mathrm{v})$ HEPES buffered solution. ( $\left.c=0.01 \mathrm{M}, \lambda_{\mathrm{ex}}=455\right)$.

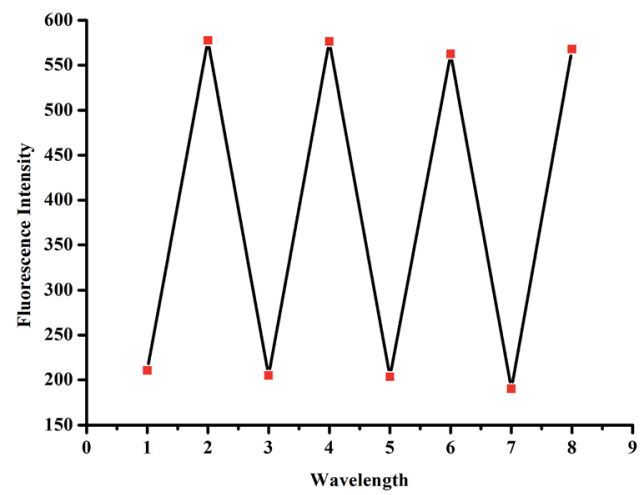

Fig. 8 Fluorescence switching cycles of $\mathrm{L} 2\left(\mathrm{c}=2.0 \times 10^{-5} \mathrm{M}\right.$, $\lambda_{\text {ex }}=455 \mathrm{~nm}$ ), controlled by alternating the addition of $\mathrm{CN}^{-}$and $\mathrm{HClO}_{4}$.

achieved balance when the concentration of $\mathrm{CN}^{-}$ions increased to 25.0 equivalent. Furthermore, as shown in Fig. S5, $\dagger$ the detection limit of the fluorescent spectrum changes calculated on the basis of $3 \delta / s$ (ref. 51 ) is $8.82 \times 10^{-7} \mathrm{~mol} \mathrm{~L}^{-1}$ for $\mathrm{CN}^{-}$, which is far lower than the WHO guideline of $1.9 \mu \mathrm{mol} \mathrm{L} \mathrm{L}^{-1}$ cyanide. $^{13}$

To further exploit the utility of the chemosensor L2 as an anion-selective sensor for $\mathrm{CN}^{-}$, competitive experiments were carried out in the presence of 10 equiv. of $\mathrm{CN}^{-}$and 50 equiv. of various anions in DMSO/ $\mathrm{H}_{2} \mathrm{O}(9: 1, \mathrm{v} / \mathrm{v})$ HEPES buffered solution. As shown in Fig. 6, none of the competing anions interfered in the detection of $\mathrm{CN}^{-}$. This result displays the highly selectivity of the chemosensor $\mathbf{L} 2$ toward $\mathrm{CN}^{-}$over the other anions analytes mentioned above.

The selectivity of $\mathbf{L} 2$ to $\mathrm{CN}^{-}$was also examined over the range of $\mathrm{pH}$ values. The detection of $\mathrm{CN}^{-}$can work well in the $\mathrm{pH}$ range of 6.0-9.0 in HEPES buffered solution in $\mathrm{DMSO} / \mathrm{H}_{2} \mathrm{O}$ $(9: 1, \mathrm{v} / \mathrm{v})$ (Fig. 7).

Moreover, the recyclability is very important for chemosensors. Therefore, we carefully investigated the reversibility of the $\mathrm{CN}^{-}$recognition properties by adding $\mathrm{H}^{+}$into the solution of $\mathrm{CN}^{-}$treated sensor $\mathbf{L} 2$. As a result, by alternating the addition of $\mathrm{CN}^{-}$and $\mathrm{HClO}_{4}$, the fluorescence of the sensor shows "off- 


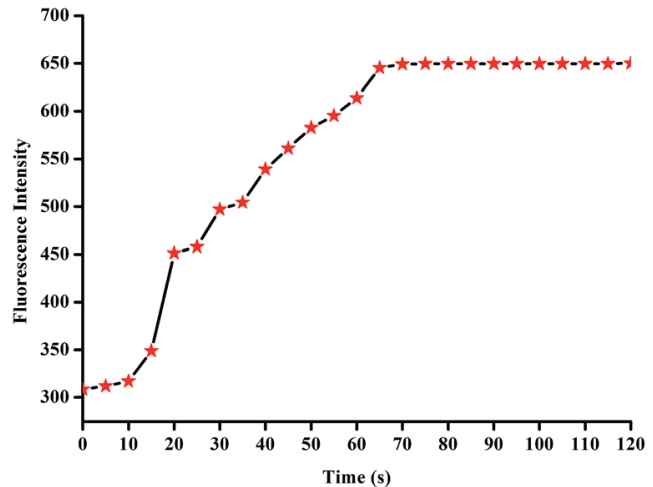

Fig. 9 Fluorescence intensity of a solution of $\mathrm{L} 2\left(c=2.0 \times 10^{-5} \mathrm{M}\right.$, $\left.\lambda_{\mathrm{ex}}=455 \mathrm{~nm}, \lambda_{\mathrm{em}}=550 \mathrm{~nm}\right)$ in DMSO $/ \mathrm{H}_{2} \mathrm{O}(9: 1, \mathrm{v} / \mathrm{v}) \mathrm{HEPES}$ buffered solution after addition of 50 equivalents $\mathrm{CN}^{-}$in water.

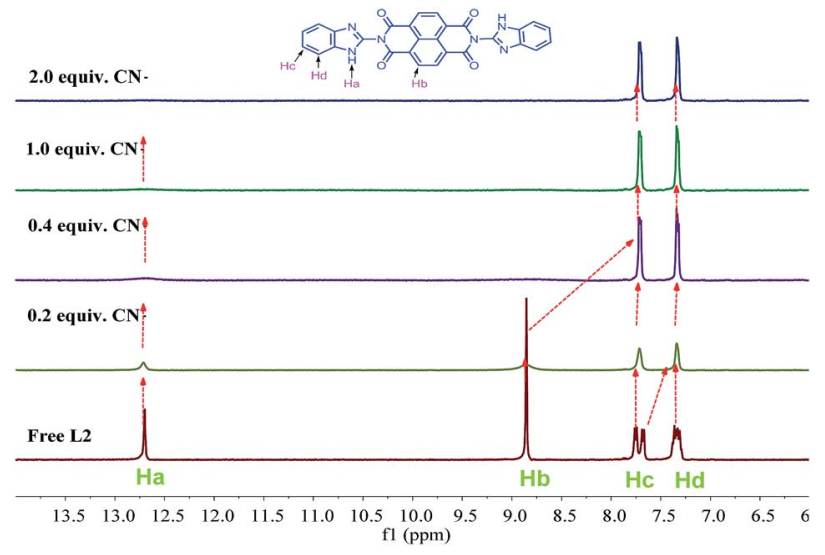

Fig. $10{ }^{1} \mathrm{H}$ NMR spectra $\left(400 \mathrm{MHz}, \mathrm{DMSO}-d_{6}\right)$ of free $\mathrm{L} 2$ and in the presence of $\mathrm{CN}^{-}$.

on-off" changes several cycles with little loss of fluorescence efficiency (Fig. 8). These properties made sensor $\mathbf{L 2}$ act as recyclable $\mathrm{CN}^{-}$sensor as well as a fluorescent switch.

In addition, it is well known that reaction-based chemosensors always have had the problem of a long response time. In our case, the detection of $\mathrm{CN}^{-}$using $\mathbf{L} 2$ was found to be relatively rapid (Fig. 9). After adding the cyanide anion, the fluorescence emission intensity of $\mathbf{L} 2$ increased and reached the plateau region in less than $1 \mathrm{~min}$, suggesting that the whole process of the $\mathrm{CN}^{-}$detection might be completed rapidly.

In order to further explore the sensing mechanism of sensor $\mathbf{L} 2$ to $\mathrm{CN}^{-}$, the ${ }^{1} \mathrm{H}$ NMR titrations were investigated. As shown in Fig. 10, before the addition of cyanide ion, the ${ }^{1} \mathrm{H}$ NMR chemical shifts of the $\mathrm{Ha}(-\mathrm{NH}), \mathrm{Hb}, \mathrm{Hc}, \mathrm{Hd}$ protons on $\mathbf{L} 2$ were at $12.71,8.86,7.72$ and $7.33 \mathrm{ppm}$, respectively. Upon the addition of $0.2-2.0$ equivalents of cyanide ion, the signal $\mathrm{Ha}(-\mathrm{NH})$ was disappeared and the $\mathrm{Hb}, \mathrm{Hc}$ protons shifted upfield. These observations obviously indicate that the sensor $\mathbf{L} 2$ were deprotonated by excess amounts of $\mathrm{CN}^{-}$, which resulted in intramolecular charge transfer. The FT-IR spectroscopy (Fig. S6†) was also support the proposed mechanism. In the FT-IR spectroscopy of $\mathbf{L} 2$, a $-\mathrm{NH}$ vibration peak appeared at $3509 \mathrm{~cm}^{-1}$,

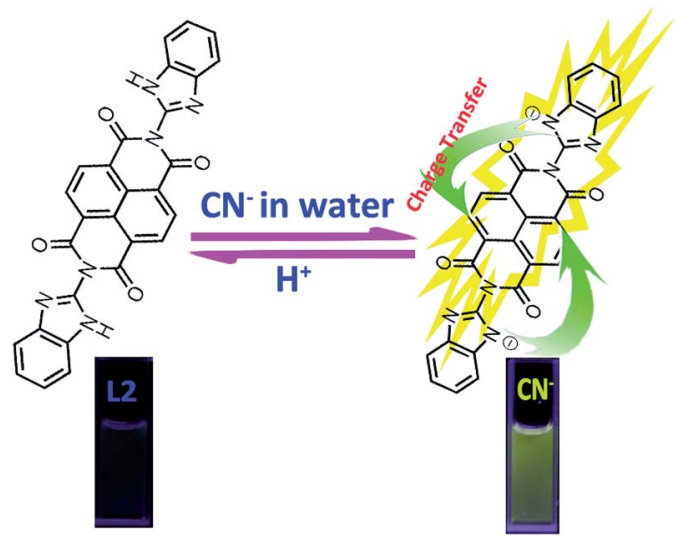

Scheme 2 The possible sensing mechanism of $\mathrm{L} 2$ reaction with $\mathrm{CN}^{-}$.

while, upon the addition of 2.0 equiv. $\mathrm{CN}^{-},-\mathrm{NH}$ vibration peak disappeared, which indicated that the deprotonation occurred. A possible mechanism for the formation of $\mathbf{L} 2-\mathbf{C N}$ is proposed in Scheme 2.

\section{Conclusions}

In summary, a fluorescent chemosensor $\mathbf{L} 2$ has been designed and synthesized by an one-step reaction. The sensor $\mathbf{L} 2$ for could rapidly detect $\mathrm{CN}^{-}$with high selectivity and sensitivity via a deprotonation and intramolecular charge transfer mechanism. The detection limit of the chemosensor $\mathbf{L} 2$ toward $\mathbf{C N}^{-}$ was $8.32 \times 10^{-7} \mathrm{~mol} \mathrm{~L}^{-1}$, other anions couldn't interfere in the $\mathrm{CN}^{-}$detection process. The detection of $\mathrm{CN}^{-}$can work well in the $\mathrm{pH}$ range of 6.0-9.0. Moreover, the $\mathrm{CN}^{-}$sensing process shows reversible properties by adding $\mathrm{H}^{+}$into the sensor $\mathbf{L 2}$ solution treated by $\mathrm{CN}^{-}$. The sensor $\mathbf{L} 2$ could act as a convenient recyclable test kits to $\mathrm{CN}^{-}$.

\section{Acknowledgements}

This study was supported by the National Natural Science Foundation of China (NSFC) (No. 21662031; 21661028; 21574104; 21262032) and the Program for Changjiang Scholars and Innovative Research Team in University of Ministry of Education of China (IRT 15R56).

\section{Notes and references}

1 C. Caltagirone and P. A. Gale, Chem. Soc. Rev., 2009, 38, 520. 2 K. P. Carter, A. M. Young and A. E. Palmer, Chem. Rev., 2014, 114, 4564.

3 S. V. Krivovichev, O. Mentré, O. I. Siidra, M. Colmont and S. K. Filatov, Chem. Rev., 2013, 113, 6459.

4 N. Busschaert, C. Caltagirone, W. V. Rossom and P. A. Gale, Chem. Rev., 2015, 115, 8038.

5 S. Dong, J. Yuan and F. Huang, Chem. Sci., 2014, 5, 247.

6 Z. Zhang, Q. Zhao, J. Yuan, M. Antonietti and F. Huang, Chem. Commun., 2014, 50, 2595. 
7 K. Yang, Y. Pei, J. Wen and Z. Pei, Chem. Commun., 2016, 52, 9316.

8 G. Yu, J. Zhou, J. Shen, G. Tang and F. Huang, Chem. Sci., 2016, 7, 4073.

9 Y. Yao, M. Xue, Z. Zhang, M. Zhang, Y. Wang and F. Huang, Chem. Sci., 2013, 4, 3667.

10 M. A. Holland and L. M. Kozlowski, Clin. Pharmacol., 1986, 5, 737.

11 R. Koenig, Science, 2000, 10, 1737.

12 F. J. Baud, Hum. Exp. Toxicol., 2007, 26, 191.

13 Guidelines for Drinking-Water Quality, World Health Organization, Geneva, 2nd edn, 1996, vol. 2.

14 F. Wissing, in Cyanide in Biology, Academic Press, London, 1981.

15 Z. Xu, X. Chen, H. N. Kim and J. Yoon, Chem. Soc. Rev., 2010, 39, 127.

16 M. Xue, X. Zhong, Z. Shaposhnik, Y. Q. Qu, F. Tamanoi, X. F. Duan and J. I. Zink, J. Am. Chem. Soc., 2011, 23, 8798.

17 Y. Yang, Q. Zhao, W. Feng and F. Li, Chem. Rev., 2013, 113, 192.

18 J. H. Hu, J. B. Li, J. Qi and J. J. Chen, New J. Chem., 2015, 39, 843.

19 Y. Shiraishi, M. Nakamura, N. Hayashi and T. Hirai, Anal. Chem., 2016, 88, 6805.

20 L. J. Tang and M. J. Cai, Sens. Actuators, B, 2012, 173, 862.

21 S. C. Wei, P. H. Hsu, Y. F. Lee, Y. W. Lin and C. C. Huang, ACS Appl. Mater. Interfaces, 2012, 4, 2652.

22 I. J. Kim, M. Ramalingam and Y. A. Son, Sens. Actuators, B, 2017, 246, 319.

23 Y. Y. Guo, X. L. Tang, F. P. Hou, J. Wu, W. Dou, W. W. Qin, J. X. Ru, G. L. Zhang, W. S. Liu and X. J. Yao, Sens. Actuators, $B$, 2013, 181, 202.

24 B. A. Rao, J. Y. Lee and Y. A. Son, Spectrochim. Acta, Part A, 2014, 127, 268.

25 T. B. Wei, G. Y. Wu, B. B. Shi, Q. Lin, H. Yao and Y. M. Zhang, Chin. J. Chem., 2014, 32, 1238.

26 V. Kumar, M. P. Kaushik, A. K. Srivastava, A. Pratap, V. Thiruvenkatam and T. N. Row, Anal. Chim. Acta, 2010, 663, 77.

27 M. Shahid, S. S. Razi, P. Srivastava, R. Ali, B. Maiti and A. Misra, Tetrahedron, 2012, 68, 9076.

28 Y. H. Jeong, C. H. Lee and W. D. Jang, Chem.-Asian J., 2012, 7, 1562.
29 Y. M. Kim, H. Y. Zhao and F. P. Gabbai, Angew. Chem., 2009, 121, 5057; Angew. Chem. Int. Ed., 2009, 48, 4957.

30 J. Jo, A. Olasz, C. H. Chen and D. Lee, J. Am. Chem. Soc., 2013, 135, 3620.

31 R. Guliyev, S. Ozturk, E. Sahin and E. U. Akkaya, Org. Lett., 2012, 14, 1528.

32 M. Dong, Y. Peng, Y. M. Dong, N. Tang and Y. W. Wang, Org. Lett., 2012, 14, 130.

33 Y. M. Dong, Y. Peng, M. Dong and Y. W. Wang, J. Org. Chem., 2011, 76, 6962.

34 L. Yang, X. Li, J. B. Yang, Y. Qu and J. L. Hua, ACS Appl. Mater. Interfaces, 2013, 5, 1317.

35 G. L. Fu and C. H. Zhao, Tetrahedron, 2013, 69, 1700.

36 Y. D. Lin, Y. S. Pen, W. T. Su, K. L. Liau, Y. S. Wen, C. H. Tu, C. H. Sun and T. J. Chow, Chem.-Asian J., 2012, 7, 2864.

37 R. Misra, T. Jadhav, B. Dhokale and S. M. Mobin, Dalton Trans., 2015, 44, 16052.

38 T. S. Reddy, R. Maragani and R. Misra, Dalton Trans., 2016, 45, 2549.

39 R. Maragani, T. S. Reddy and R. Misra, Tetrahedron Lett., 2016, 57, 3853.

40 Q. Lin, T. T. Lu, X. Zhu, T. B. Wei, H. Li and Y. M. Zhang, Chem. Sci., 2016, 7, 5341.

41 W. J. Qu, T. B. Wei, Q. Lin, W. T. Li, J. X. Su, G. Y. Liang and Y. M. Zhang, Sens. Actuators, B, 2016, 232, 115.

42 J. Chen, Q. Lin, Q. Li, W. T. Li, Y. M. Zhang and T. B. Wei, RSC Adv., 2016, 6, 86627.

43 B. B. Shi, P. Zhang, T. B. Wei, H. Yao, Q. Lin and Y. M. Zhang, Chem. Commun., 2013, 49, 7812.

44 Q. Lin, F. Zheng, L. Liu, P. P. Mao, Y. M. Zhang, H. Yao and T. B. Wei, RSC Adv., 2016, 6, 111928.

45 Q. Lin, P. P. Mao, L. Liu, J. Liu, Y. M. Zhang, H. Yao and T. B. Wei, RSC Adv., 2017, 7, 11206.

46 Y. L. Leng, J. H. Zhang, Q. Li, Y. M. Zhang, Q. Lin, H. Yao and T. B. Wei, New J. Chem., 2016, 40, 8607.

47 W. J. Qu, W. T. Li, H. L. Zhang, T. B. Wei, Q. Lin, H. Yao and Y. M. Zhang, Sens. Actuators, B, 2017, 242, 430.

48 Q. Lin, X. Liu, T. B. Wei and Y. M. Zhang, Chem.-Asian J., 2013, 8, 3015.

49 T. S. Reddy, R. Maragani, B. Dhokale, S. M. Mobin and R. Misra, RSC Adv., 2016, 6, 7746.

50 S. Tsuzuki, K. Honda, T. Uchimaru, M. Mikami and K. Tanabe, J. Am. Chem. Soc., 2002, 124, 104.

51 Analytical Methods Committee, Analyst, 1987, 112, 199. 